\title{
Температурная зависимость порогового тока и выходной мощности квантово-каскадного лазера с частотой генерации 3.3 ТГц
}

\author{
() Р.А. Хабибуллин ${ }^{1}$, Н.В. Щаврук ${ }^{1}$, Д.С. Пономарев ${ }^{1}$, Д.В. Ушаков ${ }^{2}$, А.А. Афоненко ${ }^{2}$, \\ И.С. Васильевский ${ }^{3}$, А.А Зайцев ${ }^{4}$, А.И. Данилов ${ }^{5}$, О.Ю. Волков ${ }^{6}$, \\ В.В. Павловский ${ }^{6}$, К.В. Маремьянин ${ }^{7}$, В.И. Гавриленко ${ }^{7}$ \\ ${ }^{1}$ Институт сверхвысокочастотной полупроводниковой электроники Российской академии наук, \\ 117105 Москва, Россия \\ ${ }^{2}$ Белорусский государственный университет, \\ 220030 Минск, Беларусь \\ ${ }^{3}$ Национальный исследовательский ядерный университет „МИФИ“, \\ 115409 Москва, Россия \\ ${ }^{4}$ Национальный исследовательский университет „МИЭТ“, \\ 124498 Москва, Зеленоград, Россия \\ ${ }^{5}$ АО НИИ „Полюс“ им. М.Ф. Стельмаха, \\ 117342 Москва, Россия \\ ${ }^{6}$ Институт радиотехники и электроники им. В.А. Котельникова Российской академии наук, \\ 125009 Москва, Россия \\ ${ }^{7}$ Институт фризики микроструктур Российской академии наук, \\ 603950 Нижний Новгород, Россия \\ E-mail: khabibullin@isvch.ru
}

(Получена 4 июня 2018 г. Принята к печати 14 июня 2018 г.)

Предложена конструкция активной области квантово-каскадного лазера терагерцового диапазона частот на основе трех туннельно-связанных квантовых ям $\mathrm{GaAs} / \mathrm{Al}_{0.15} \mathrm{Ga}_{0.85} \mathrm{As}$ с резонансно-фононным дизайном. Рассчитаны уровни энергии, матричные элементы дипольных переходов и спектры усиления в зависимости от напряженности приложенного электрического поля $F$ и температуры. Показано, что максимальное усиление реализуется на частоте 3.37 ТГц при $F=12.3$ кВ/см. На основе предложенной конструкции изготовлен квантово-каскадный лазер с двойным металлическим волноводом, излучающий на частоте $\sim 3.3$ ТГц при $T_{\max } \sim 84 \mathrm{~K}$. Из зависимости выходной мощности от температуры определена энергия активации $E_{a}=23$ мэВ испускания LO-фононов при рекомбинации электронов с верхнего лазерного уровня на нижний.

DOI: 10.21883/FTP.2018.11.46581.03

\section{1. Введение}

В настоящее время квантово-каскадные лазеры (ККЛ) являются компактными твердотельными когерентными источниками терагерцового излучения в диапазоне от 1.2 до 5.0 ТГц. Большая выходная мощность [1], возможность перестройки частоты [2] и получения узких линий генерации [3] делает ККЛ наиболее перспективным ТГц-источником для реализации терагерцовой спектроскопии нового поколения [4], систем терагерцовой визуализации в реальном времени [5], а также для использования в качестве локального осциллятора для гетеродинного детектирования [6].

На сегодняшний день одной из главных проблем ТГц ККЛ являются низкие рабочие температуры. Для ТГц ККЛ с частотами вблизи 3 ТГц максимальные рабочие температуры составляют $117 \mathrm{~K}$ в непрерывном режиме и $199.5 \mathrm{~K}$ при импульсной накачке. Данные параметры были получены в ТГц ККЛ с резонансно-фононным дизайном, когда в качестве механизма накачки верхнего лазерного уровня используется резонансное туннелирование, а в качестве механизма опустошения нижнего лазерного уровня используется резонансное испускание продольного оптического фонона (LO-фонона).
Мощность излучения ТГц ККЛ с частотами вблизи 3 ТГц достигает 230 мВт в непрерывном режиме [1]. Однако при продвижении от 3 к 1 ТГц и от 3 к 5 ТГц выходные мощности и рабочие температуры существенно снижаются, что связано с различными физическими ограничениями. Со стороны „низких“ частот это связано с тем, что величина энергетического зазора между рабочими уровнями (около 8 мэВ для частоты 2 ТГц) становится сопоставима с энергетическим уширением подзон (единицы мэВ). При этом уменьшается эффективность инжекции электронов на верхний лазерный уровень, что требует поиска новых схем работы ТГц ККЛ, в том числе новых способов инжекции электронов. Со стороны „высоких“ частот расстояние между рабочими уровнями (около 20 мэВ для частоты 5 ТГц) становится сопоставимо с энергией LO-фонона в GaAs $\left(E_{\mathrm{LO}}=36\right.$ мэB), что приводит к испусканию LO-фононов „горячими“ электронами на верхнем рабочем уровне и уменьшению инверсной населенности. Следует отметить, что в области низких частот 1-2 ТГц наблюдается рост потерь, обусловленных поглощением излучения свободными носителями заряда, а в области частот свыше 6 ТГц - резонансным поглощением на ТО-фононах [7,8], что также ограничивает частотный диапазон работы ТГц ККЛ. 
Одним из подходов по увеличению рабочих температур ТГц ККЛ является переход на полупроводниковые материалы с большей энергией LO-фононов (GaN $E_{\mathrm{LO}}=90 \mathrm{мэB}, \mathrm{ZnO}-E_{\mathrm{LO}}=72$ мэВ и др.) $[9,10]$. Другой подход основан на разработке новых схем работы ТГц ККЛ на основе GaAs/AlGaAs, где апробируются новые способы инжекции электронов [11], дизайны с подавлением паразитных каналов проводимости [12] и использование $\Gamma-X$ междолинного транспорта в GaAs [13].

В работах [14-18] было показано, что при увеличении температуры в ТГц ККЛ возникают следующие „паразитные“ эффекты - обратный заброс электронов на нижний лазерный уровень, температурная активация испускания LO-фононов „горячими“ электронами на верхнем рабочем уровне, уширение контура усиления и утечка электронов в континуум. Как правило, оптимизация дизайна ТГц ККЛ для минимизации одного „паразитного“ эффекта контрпродуктивна для других „паразитных“ механизмов. Например, в ТГц ККЛ с резонансно-фононным дизайном и вертикальными излучающими переходами доминирующим механизмом ограничения максимальной рабочей температуры $T_{\max }$ является температурная активация испускания LO-фононов. Для уменьшения влияния данного „паразитного“ эффекта используют диагональные (пространственно не прямые) излучательные переходы, что, однако, не позволило существенно увеличить $T_{\max }$ из-за утечки электронов в континуум [14].

Цель данной работы заключается в исследовании влияния температуры на пороговый ток и выходную мощность изготовленного ТГц ККЛ на основе предложенной конструкции активной области, состоящей из трех $\mathrm{GaAs} / \mathrm{Al}_{0.15} \mathrm{Ga}_{0.85} \mathrm{As}$ туннельно-связанных квантовых ям (КЯ) с резонансно-фононным дизайном.

\section{2. Методика эксперимента}

\section{1. Конструкция активной области терагерцового квантово-каскадного лазера}

Предложенная конструкция активной области ТГц ККЛ содержала 228 каскадов, соответствующих суммарной толщине $\sim 10$ мкм. Один каскад представляет последовательность трех туннельно-связанных квантовых ям (широкая КЯ - инжектор/экстрактор электронов и двойная лазерная КЯ - излучатель ТГц фотона). Толщины слоев одного каскада в нм имеют следующие значения: 4.2/ $\underline{16.1} / 4.8 / \underline{9.6} / 2.0 / \underline{7.3}$, где подчеркнутым шрифтом обозначены слои КЯ из GaAs. Центральная часть широкой КЯ легировалась донорной примесью $\mathrm{Si}$ со слоевой концентрацией $3 \cdot 10^{10} \mathrm{~cm}^{-2}$.

Энергии, волновые функции, матричные элементы дипольных переходов, а также профиль потенциальной энергии находились $k p$-методом в расширенной модели Бастарда $[19,20]$ на основе самосогласованного решения уравнений Шредингера и Пуассона. Степень заполнения уровней энергий и соответствующие квазиуровни Ферми находились путем численного решения системы балансных уравнений [21,22]. Коэффициент усиления $g$ для внутриподзонных переходов в зависимости от частоты излучения находился в многоуровневом приближении с учетом несимметричного контура линии усиления [23] с параметром уширения $\sim 9$ мэВ. При вычислении высота потенциальных барьеров в зоне проводимости полагалась равной $\Delta E_{c}=133$ мэВ. Эффективные массы электронов полагались $m^{*}=0.080 m_{0}$ для барьерных слоев $\mathrm{Al}_{0.15} \mathrm{Ga}_{0.85} \mathrm{As}$ и $m^{*}=0.067 m_{0}$ для GaAs КЯ [24].

На рис. 1 приведены результаты расчета зонной структуры и волновых функций предложенной конструкции активной области ТГц ККЛ. При увеличении напряженности электрического поля $(F)$ исследуемая система имеет три характерных состояния, когда края различных подзон сближаются по энергии, что приводит к увеличению вертикального переноса заряда в структуре $[25,26]$. Инверсная населенность лазерных уровней возникает, когда энергия „нижнего“ уровня инжектора $E_{6}$ становится больше, чем энергия „нижнего“ лазерного уровня $E_{3}$. При $F=12.3$ кВ/см происходит выравнивание энергии „нижнего“ уровня инжектора $E_{6}$ и „верхнего“ лазерного уровня $E_{5}$, а также расстояние между „верхним“ и „нижним“ уровнями инжектора равно энергии LO-фонона $\left(E_{1}^{\prime}-E_{6}=E_{\mathrm{LO}}\right)$, что соответствует максимальному усилению исследуемой структуры.

Предложенная конструкция имеет два основных излучательных перехода: 1) между уровнями 5 и 3 с энергией $E_{53}=12.95$ мэВ (3.1 ТГц), матричный элемент дипольного перехода $z_{53}=4.3 \mathrm{Hм}$ и сила осциллятора $\left.f_{53}=0.35 ; 2\right)$ между уровнями 6 и 3 с $E_{63}=14.80$ мэВ $\left(3.59\right.$ ТГц), $z_{63}=3.4 \mathrm{Hм}$ и $f_{63}=0.26$. Таким образом, при усреднении по основным переходам $5 \rightarrow 3$ и $6 \rightarrow 3$ длина волны генерации составляет $\sim 90.8$ мкм, что соответствует частоте 3.3 ТГц.

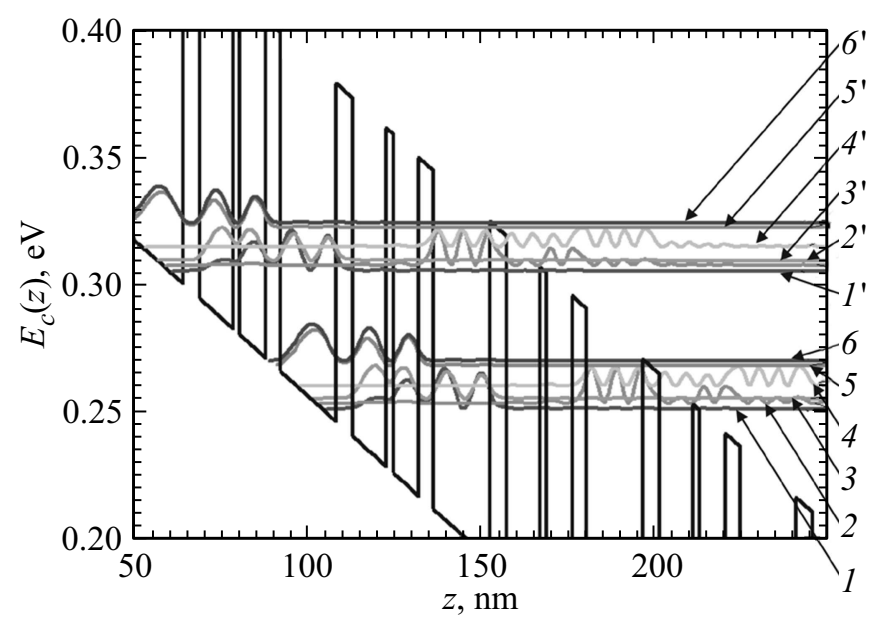

Рис. 1. Диаграмма зоны проводимости $E_{c}(z)$, уровни энергии и квадраты модулей волновых функций электронов в электрическом поле $F=12.3$ кВ/см. Цифрами $1,2,3,4,5,6$ и $1^{\prime}, 2^{\prime}, 3^{\prime}$, $4^{\prime}, 5^{\prime}, 6^{\prime}$ отмечены волновые функции, которые соответствуют уровням энергий двух каскадов структуры ТГц ККЛ. 


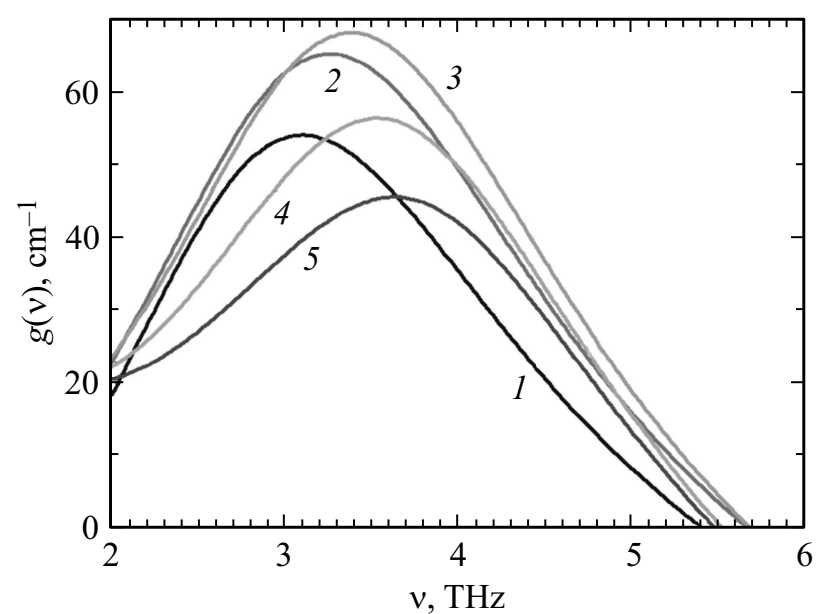

Pис. 2. Спектры усиления структуры ТГц ККЛ для различных значений приложенного электрического поля $F=11.9$ (1), 12.1 (2), 12.3 (3), 12.5 (4), 12.7 (5) кВ/см при $T=50 \mathrm{~K}$.

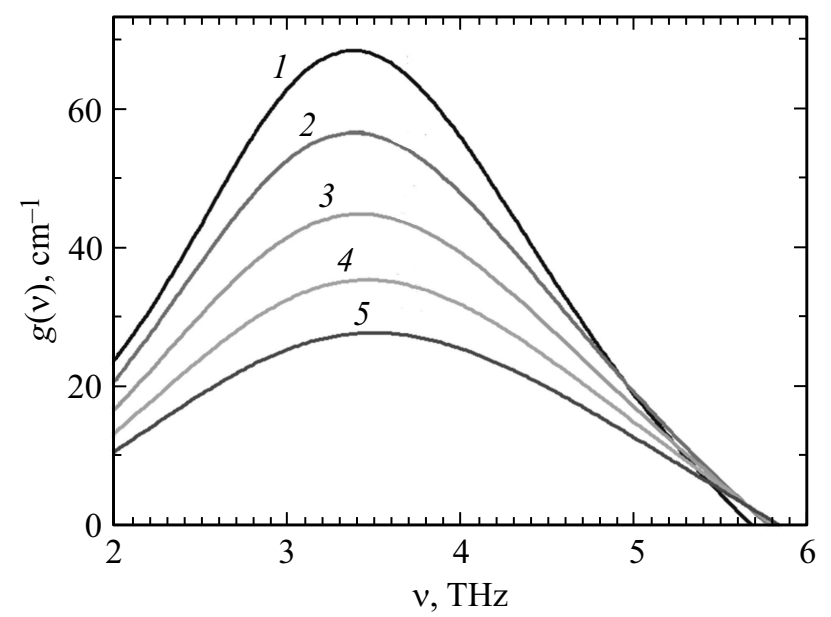

Рис. 3. Спектры усиления структуры ТГц ККЛ при $T=50$ (1), 100 (2), 150 (3), 200 (4), 250 (5) К и $F=12.3$ кВ/см.

На рис. 2 представлены рассчитанные спектры усиления структуры ТГц ККЛ при $T=50 \mathrm{~K}$ и различных значениях приложенного электрического поля. Видно, что с ростом $F$ происходит смещение максимума коэффициента усиления в высокочастотную область, что связано с перестройкой „верхних“ $E_{5}$ и $E_{6}$ и „нижнего“ $E_{3}$ рабочих уровней, а также изменением энергий $E_{1^{\prime} 5}$ и $E_{1^{\prime} 6}$. При $F=12.3 \mathrm{\kappa B} / \mathrm{cm}$ достигаются наилучшие условия по энергетическому выравниванию уровней, что приводит к максимальному значению коэффициента усиления $g_{\max } \sim 70 \mathrm{~cm}^{-1}$ на частоте $\sim 3.37$ ТГц.

Увеличение температуры приводит к активации испускания LO-фононов ,горячими“ электронами на уровнях $E_{5}$ и $E_{6}$, что уменьшает населенность „верхних“ лазерных уровней. Это приводит к уменьшению инверсной населенности рабочих лазерных уровней и, как следствие, уменьшению коэффициента усиления ТГц ККЛ (см. рис. 3).

\section{2. Изготовление терагерцового квантово-каскадного лазера}

Многослойная гетероструктура $\mathrm{GaAs} / \mathrm{Al}_{0.15} \mathrm{Ga}_{0.85} \mathrm{As}$ была выращена методом молекулярно-лучевой эпитаксии на полуизолирующей подложке GaAs диаметром 3 дюйма в компании „TrionTechnology“ (г. Темпе, Аризона, США). Гетероструктура состояла из активной области, которая была заключена между верхним и нижним контактными слоями. Верхний контактный слой состоял из 50 нм $n^{+}$-GaAs c концентрацией легирования $5 \cdot 10^{18} \mathrm{~cm}^{-3}, 10$ нм $n^{+}$-GaAs с концентрацией легирования $5 \cdot 10^{19} \mathrm{~cm}^{-3}$ и $3.5 \mathrm{Hм}$ пассивирующего слоя $\mathrm{GaAs}$, выращенного при пониженной температуре роста $250^{\circ} \mathrm{C}$. Нижний контактный слой состоял из 800 нм $n^{+}$-GaAs c концентрацией легирования $5 \cdot 10^{18} \mathrm{~cm}^{-3}$. Для создания двойного металлического волновода под нижним контактным слоем был выращен стоп-слой $\mathrm{Al}_{0.91} \mathrm{Ga}_{0.09} \mathrm{As}$ толщиной 200 нм.

Для изготовления лазерных полосков с двойным металлическим волноводом $\mathrm{Au}-\mathrm{Au}$ использовалась традиционная последовательность технологических операций, которая описана в $[27,28]$. При изготовлении резонатора Фабри-Перо использовалась операция раскалывания изготовленных лазерных полосков. Для улучшения качества сколов подложка-носитель $n^{+}$-GaAs механически утончалась до толщины $\sim 150$ мкм, что также улучшает отвод тепла от ТГц ККЛ. Кроме того, операцию раскалывания упрощает формирование лазерных полосков с так называемыми плечами, когда при плазмохимическом травлении гетероструктуры формируются вертикальные стенки на глубину $\sim 8.5$ мкм, а оставшиеся $\sim 1.5$ мкм имеют пологий профиль.

Изготовленные лазерные полоски с длиной 1 мм и шириной 100 мкм монтировались на медный теплоотвод типа $C$-mount, который являлся нижним контактом к структуре. Верхний контакт разваривался с помощью семи золотых проволок для однородности распределения тока накачки по площади лазерного полоска. Использование двойного металлического волновода для ТГц-излучения с длиной волны $\sim 90$ мкм при геометрических размерах торца лазерного полоска $10 \times 100$ мкм приводит к большому значению коэффициента отражения $R \sim 0.9$. Для согласования открытого конца волновода со свободным пространством к одному из торцов ТГц ККЛ прижималась гиперполусферическая сапфировая линза. Кроме того, ТГц ККЛ с двойным металлическим волноводом имеет большую расходимость ТГц-пучка, поэтому использование линзы позволяет сфокусировать пучок в окно криостата.

\section{3. Экспериментальные результаты и обсуждение}

Исследования вольт-амперных (BАХ) и излучательных характеристик изготовленных ТГц ККЛ проводи- 
лись в диапазоне температур от 4.2 до $78 \mathrm{~K}$ в импульсном режиме с длительностью импульсов 1-10 мкс и скважностью 1000. Лазерное излучение детектировалось охлаждаемым $(4.2 \mathrm{~K})$ кремниевым болометром BrukerOptik 3340, входное окно которого располагалось напротив выходного окна криостата с ТГц ККЛ. В проводимых экспериментах не использовалась продувка азотом зазора между окнами болометра и криостата, поэтому часть излучения ТГц ККЛ поглощалась парами воды в окружающей атмосфере. Спектры излучения измерялись с помощью вакууммированного фурьеспектрометра Bruker Vertex80v, работающего в режиме пошагового сканирования.

На рис. 4 представлены измеренные ВАХ и зависимости интенсивности интегрального излучения от тока при 20 и $55 \mathrm{~K}$. Измеренные ВАХ имеют типичный вид для ТГц ККЛ с резонансно-фононным дизайном, когда за счет выравнивания уровней энергий при увеличении напряженности электрического поля наблюдаются характерные изломы. После второго излома ВАХ (ток около $0.85-0.86$ А для $20 \mathrm{~K}$ ), который соответствует порогу генерации, возникает резкий рост интенсивности излучения. При этом для температур 20 и $55 \mathrm{~K}$ наблюдаются плавные (без изломов) зависимости интегральной интенсивности излучения от тока. Это свидетельствует об отсутствии перескоков между модами (mode hopping) в ТГц ККЛ.

Пиковая мощность ТГц ККЛ достигается при напряжении около $17 \mathrm{~B}$ (токе около $1 \mathrm{~A}$ ), что соответствует напряженности электрического поля в структуре $F=14.8$ кВ/см. Отличие расчетного $(F=12.3$ кВ/см $)$ и экспериментального значений $F$ для достижения максимума усиления в ТГц ККЛ связано с отсутствием учета контактных сопротивлений в расчете. При дальнейшем увеличении напряжения на лазере наблюдается резкий

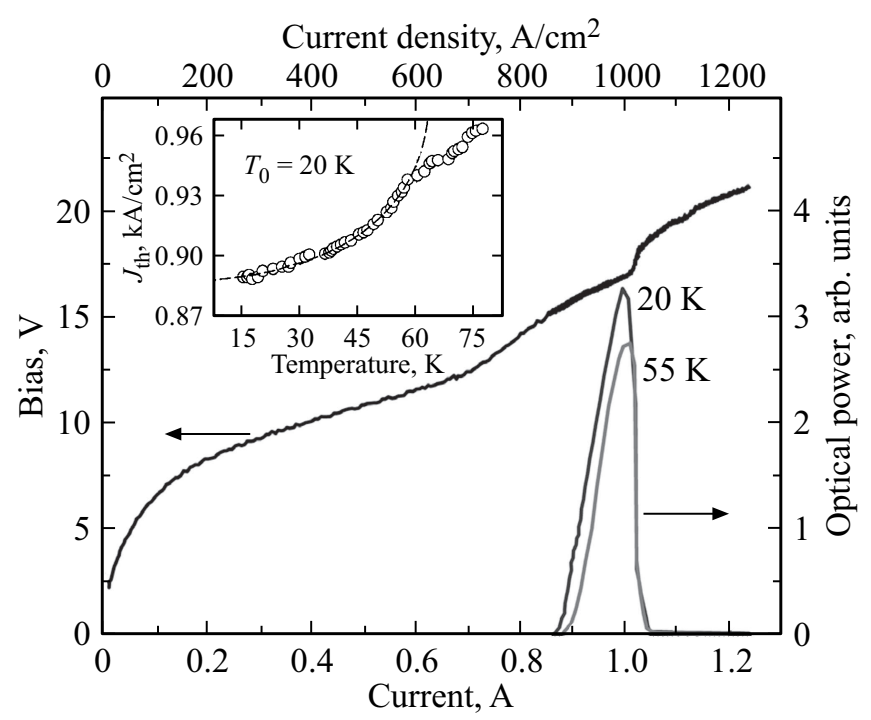

Рис. 4. ВАХ при $T=20 \mathrm{~K}$ и зависимости интенсивности излучения ТГц ККЛ от тока, измеренные при 20 и $55 \mathrm{~K}$. На вставке приведена зависимость порогового тока от температуры.

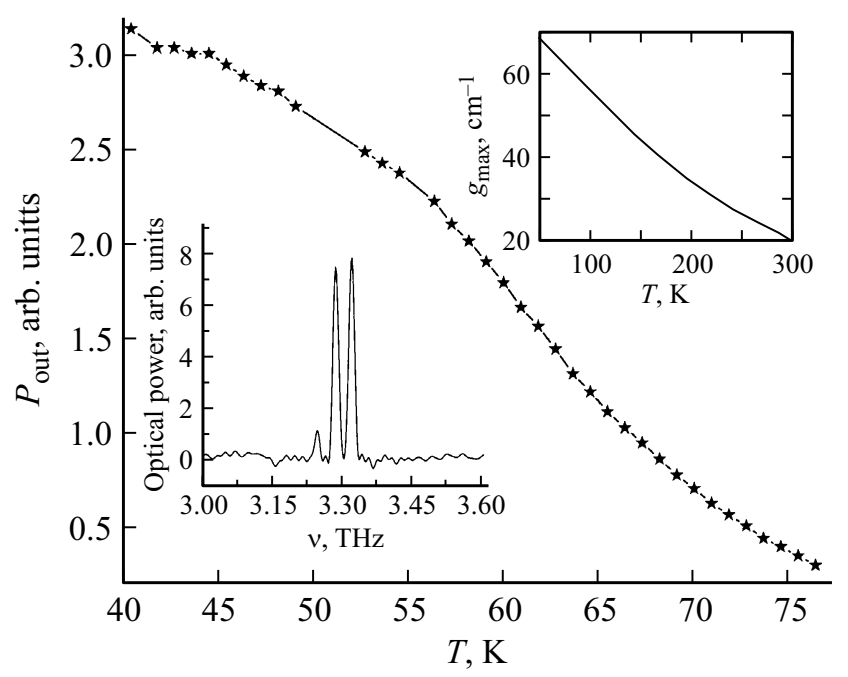

Рис. 5. Зависимость пиковой выходной мощности от рабочей температуры ТГц ККЛ. На вставке вверху приведена рассчитанная зависимость $g_{\max }$ от температуры. На вставке внизу приведен спектр излучения ТГц ККЛ при $58 \mathrm{~K}$ и токе $\sim 1.0 \mathrm{~A}$.

спад интенсивности излучения до прекращения генерации при токе около $1.05 \mathrm{~A}$.

На вставке к рис. 4 приведена зависимость порогового тока $J_{\text {th }}$ от температуры для изготовленного ТГц ККЛ. При увеличении температуры от 15 до $78 \mathrm{~K}$ увеличение $J_{\text {th }}$ составило около $7 \%$. Используя эмпирическое выражение для зависимости $J_{\text {th }}$ от температуры $J_{\text {th }} \sim \exp \left(T / T_{0}\right)$, можно определить характеристическую температуру, которая составила $T_{0}=20 \mathrm{~K}$. После $60 \mathrm{~K}$ наблюдается более пологий участок зависимости $J_{\text {th }}(T)$, который нельзя описать указанным выше эмпирическим выражением с $T_{0}=20 \mathrm{~K}$. Кроме того, исследования зависимости $J_{\text {th }}(T)$ не позволяют определить, какие физические механизмы ухудшают характеристики ТГц ККЛ при увеличении температуры.

На рис. 5 представлена зависимость пиковой выходной мощности $P_{\text {out }}$ от температуры в диапазоне от 40 до $78 \mathrm{~K}$. Нужно отметить, что при температуре $78 \mathrm{~K}$ продолжала наблюдаться лазерная генерация. Используя экстраполяцию кривой $P_{\text {out }}(T)$, можно оценить максимальную рабочую температуру у изготовленного лазера $T_{\max } \sim 84 \mathrm{~K}$. При увеличении температуры от 40 до $58 \mathrm{~K}$ наблюдается незначительное уменьшение мощности излучения ТГц ККЛ на 35\%, что позволяет использовать для охлаждения лазера откачку паров азота.

При $58 \mathrm{~K}$ был измерен спектр излучения ТГц ККЛ (см. нижнюю вставку на рис. 5), в котором присутствуют три эквидистантные спектральные линии 3.24 , 3.28 и 3.32 ТГц, соответствующие продольным модам Фабри-Перо с $\Delta f=c / 2 n L=40$ ГГц, где $c$ - скорость света в вакууме, $n$ - эффективный показатель преломления и $L-$ длина резонатора. Наибольшую интенсивность имеет спектральная линия с частотой 3.32 ТГц, что хорошо коррелирует с рассчитанным спектром уси- 


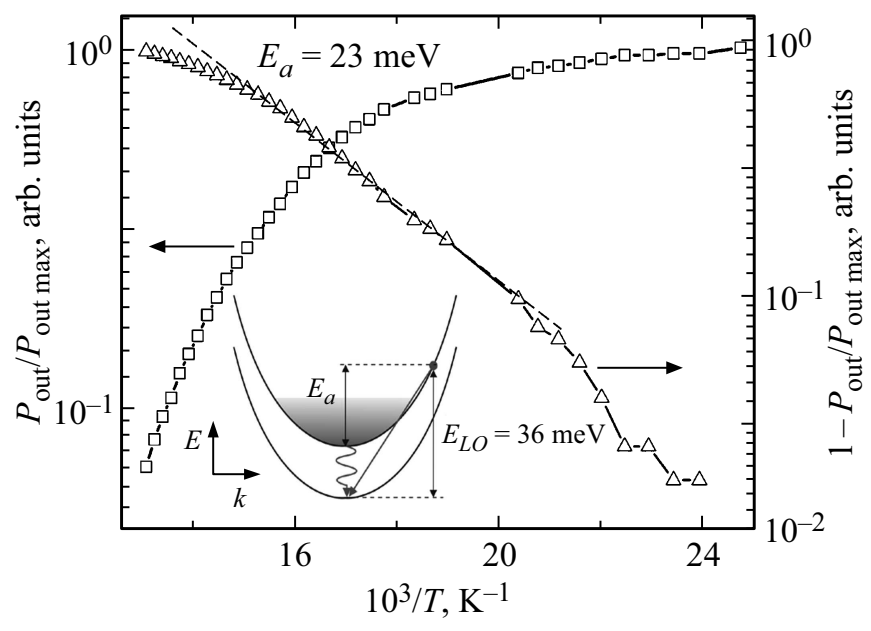

Рис. 6. График Аррениуса зависимости нормированной выходной мощности $P_{\text {out }} / P_{\text {out } \max }$ и $\left(1-P_{\text {out }} / P_{\text {out } \max }\right)$ от температуры. Вставка иллюстрирует процесс испускания LO-фонона электроном, термически возбужденным до энергии $E_{a}$.

ления, на котором максимуму усиления соответствует частота 3.37 ТГц (см. рис. 2).

При температурах выше $60 \mathrm{~K}$ наблюдается более резкий спад $P_{\text {out }}$ от температуры. Можно предположить, что в данном температурном диапазоне доминирующим механизмом рассеяния становится температурная активация испускания LO-фононов. При этом рассчитанная зависимость $g_{\max }$ от температуры (см. верхнюю вставку на рис. 5) демонстрирует плавное уменьшение с ростом $T$. Скорее всего, при низких температурах (до $60 \mathrm{~K}$ ) более медленный спад $P_{\text {out }}(T)$ связан с утечкой электронов с „нижнего“ лазерного уровня $E_{3}$ через уровень $E_{2}$ в континуум, что не учитывалось при расчете зависимости $g_{\max }(T)$. Данный механизм депопуляции „нижнего“ лазерного уровня $E_{3}$ позволял частично компенсировать депопуляцию „верхних“ лазерных уровней $E_{5}$ и $E_{6}$ за счет температурной активации испускания LO-фононов. Учет утечки электронов в континуум позволил существенно улучшить корреляцию расчетных и экспериментальных зависимостей $P_{\text {out }}(T)$ в работах $[18,29]$.

На основе метода, предложенного в статье [30], из экспериментальной зависимости $P_{\text {out }}(T)$ определялась характеристическая энергия активации $E_{a}$ доминирующего механизма рассеяния в изготовленном ТГц ККЛ. Из отрицательного наклона $\ln \left(1-P_{\text {out }} / P_{\text {out max }}\right)$, построенного от 1000/T (график Аррениуса), определялось значение $E_{a}$, которое составило 23 мэВ (см. рис. 6). Исследуемый ТГц ККЛ имеет частоту генерации около 3.3 ТГц, что соответствует энергии ТГц фотона $h v=13.65$ мэВ. Таким образом, при увеличении температуры все большее число электронов с „верхних“ лазерных уровней $E_{5}$ и $E_{6}$ термически возбуждается до энергии $E_{a}=E_{\mathrm{LO}}-h v$, что активирует рекомбинацию электронов на нижний лазерный уровень с испусканием LO-фонона (см. вставку на рис. 6).

\section{4. Заключение}

В работе предложена конструкция активной области квантово-каскадного лазера терагерцового диапазона частот с максимальным коэффициентом усиления $g_{\max } \sim 70 \mathrm{~cm}^{-1}$ на частоте $\sim 3.37$ ТГц при напряженности электрического поля $F=12.3$ кВ/см и температуре $T=50 \mathrm{~K}$. Проведен расчет спектров усиления ТГц ККЛ в зависимости от напряженности приложенного электрического поля и температуры. Изготовлены ТГц ККЛ с двойным металлическим волноводом $\mathrm{Au}-\mathrm{Au}$ шириной 100 мкм и резонатором Фабри-Перо длиной 1000 мкм. Порог генерации у изготовленных ТГц ККЛ достигается при токе $0.85-0.86$ А для $20 \mathrm{~K}$. Проведено исследование влияния температуры на пороговый ток и выходную мощность изготовленного ТГц ККЛ, излучающего в области $\sim 3.3$ ТГц с максимальной рабочей температурой $T_{\max } \sim 84 \mathrm{~K}$. Из зависимости порогового тока от температуры определена характеристическая температура $T_{0}=20 \mathrm{~K}$. Показано, что при увеличении температуры от 40 до $58 \mathrm{~K}$ наблюдается незначительное уменьшение мощности излучения ТГц ККЛ на $\sim 35 \%$, что позволяет использовать для охлаждения лазера откачку паров азота. Из графика Аррениуса выходной мощности от температуры определена характеристическая энергия $E_{a}=23$ мэВ, которая необходима для температурной активации испускания LO-фононов при рекомбинации электронов с верхнего на нижний лазерные уровни.

Работа выполнена при финансовой поддержке грантов РФФИ № 17-02-00070 А, 18-52-00011 Бел_а и гранта БРФФИ № Ф18Р-107. Экспериментальная часть работы по изготовлению ТГц ККЛ выполнена Н.В. Щавруком и Д.С. Пономаревым при финансовой поддержке гранта РНФ № 18-19-00493.

\section{Список литературы}

[1] X. Wang, C. Shen, T. Jiang, Z. Zhan, Q. Deng, W. Li, W. Wu, N. Yang, W. Chu, S. Duan. AIP Adv., 6 (7), 075210 (2016).

[2] Q. Qin, J.L. Reno, Q. Hu. Optics Lett., 36 (5), 692 (2011).

[3] J.R. Gao, J.N. Hovenier, Z.Q. Yang, J.J.A. Baselmans, A. Baryshev, M. Hajenius, T.M. Klapwijk, A.J.L. Adam, T.O. Klaassen, B.S. Williams, S. Kumar, Q. Hu, J.L. Reno. Appl. Phys. Lett., 86 (24), 244104 (2005).

[4] B. Roben, X. Lu, M. Hempel, K. Biermann, L. Schrottke, H. Grahn. Opt. Express, 25 (14), 16282 (2017).

[5] M. Wienold, T. Hagelschuer, N. Rothbart, L. Schrottke, K. Biermann, H.T. Grahn, H.W. Hubers. Appl. Phys. Lett., 109 (1), 011102 (2016).

[6] B. Mirzaei, J.R.G. Silva, D. Hayton, C. Groppi, T.Y. Kao, Q. Hu, J.L. Reno, J.R. Gao. Opt. Express, 25 (24), 29587 (2017).

[7] Д.В. Ушаков, А.А. Афоненко, Р.А. Хабибуллин. Квантовая электроника: матер. XI Междунар. науч.-техн. конф. (Минск, РИВШ, 2017) с. 110.

[8] Y.J. Han, L.H. Li, J. Zhu, A. Valavanis, J.R. Freeman, L. Chen, M. Rosamond, P. Dean, A.G. Davies, E.H. Linfield. Opt. Express, 26 (4), 3814 (2018). 
[9] W. Terashima, H. Hirayama. Proc. SPIE, 9483, 948304 (2015).

[10] N.L. Biavan, M. Hugues, M.M. Bajo, J. Tamayo-Arriola, A. Jollivet, D. Lefebvre, Y. Cordier, B. Vinter, F.-H. Julien, A. Hierro, J.-M. Chauveau. Appl. Phys. Lett., 111 (23), 231903 (2017)

[11] S. Khanal, J.L. Reno, S. Kumar. Opt. Express, 23 (15), 19689 (2015).

[12] A. Albo, Y.V. Flores, Q. Hu, J.L. Reno. Appl. Phys. Lett., 111 (11), 111107 (2017).

[13] M. Roy, M.A. Talukder. J. Appl. Phys., 121 (13), 133104 (2017).

[14] M. Francki, L. Bosco, M. Beck, C. Bonzon, E. Mavrona, G. Scalari, A. Wacker, J. Faist. Appl. Phys. Lett., $112(2)$, 021104 (2018).

[15] M. Lindskog, D.O. Winge, A. Wacker. Proc. SPIE, 8846, 884603 (2013).

[16] M.S. Vitiello, G. Scalari, B. Williams, P.D. Natale. Opt. Express, 23 (4), 5167 (2015).

[17] A. Matyas, P. Lugli, C. Jirauschek. Appl. Phys. Lett., 102 (1), 011101 (2013).

[18] A. Albo, Q. Hu. Appl. Phys. Lett., 107 (24), 241101 (2015).

[19] K.H. Yoo, L.R. Ram-Mohan, D.F. Nelson. Phys. Rev. B, 39 (17), 12808 (1989).

[20] Д.В. Ушаков, И.С. Манак. Опт. и спектр., 104 (5), 847 (2008).

[21] Д.В. Ушаков, И.С. Манак. ЖПС, 74 (6), 801 (2007).

[22] Д.В. Ушаков, Ю.Г. Садофьев, N. Samal. ФТП, 46 (11), 1430 (2012).

[23] Д.В. Ушаков, В.К. Кононенко, И.С. Манак. Квант. электрон., 40 (3), 195 (2010).

[24] I. Vurgaftman, J.R. Meyer, L.R. Ram-Mohan. J. Appl. Phys., 89 (11), 5815 (2001).

[25] Р.А. Хабибуллин, Н.В. Щаврук, А.Н. Клочков, И.А. Глинский, Н.В. Зенченко, Д.С. Пономарев, П.П. Мальцев, А.А. Зайцев, Ф.И. Зубов, А.Е. Жуков, Г.Э. Цырлин, Ж.И. Алфёров. ФТП, 51 (4), 540 (2017).

[26] R.A. Khabibullin, N.V. Shchavruk, A.Y. Pavlov, A.N. Klochkov, D.S. Ponomarev, I.A. Glinskiy, P.P. Maltsev, A.E. Zhukov, G.E. Cirlin, Z.I. Alferov. Int. J. High Speed Electronics and Systems, 25 (03n04), 1640022 (2016).

[27] Р.А. Хабибуллин, Н.В. Щаврук, А.Ю. Павлов, Д.С. Пономарев, К.Н. Томош, Р.Р. Галиев, П.П. Мальцев, А.Е. Жуков, Г.Э. Цырлин, Ф.И. Зубов, Ж.И. Алфёров. ФТП, 50 (10), 1395 (2016).

[28] А.В. Иконников, К.В. Маремьянин, С.В. Морозов,В.И. Гавриленко, А.Ю. Павлов, Н.В. Щаврук, Р.А. Хабибуллин, Р.Р. Резник, Г.Э. Цырлин, Ф.И. Зубов, А.Е. Жуков, Ж.И. Алфёров. Письма в ЖТФ, 43 (7), 86 (2017).

[29] A. Albo, Q. Hu, J.L. Reno. Appl. Phys. Lett., 109 (8), 081102 (2016).

[30] A. Albo, Q. Hu. Appl. Phys. Lett., 106 (13), 131108 (2015).

\section{Temperature dependence of the threshold current and output power of quantum-cascade laser emitting at $3.3 \mathrm{THz}$}

R.A. Khabibullin ${ }^{1}$, N.V. Shchavruk' ${ }^{1}$, D.S. Ponomarev' ${ }^{1}$, D.V. Ushakov ${ }^{2}$, A.A. Afonenko ${ }^{2}$, I.S. Vasil'evskii ${ }^{3}$, A.A. Zaycev ${ }^{4}$, A.I. Danilov ${ }^{5}$, O.Yu. Volkov ${ }^{6}$, V.V. Pavlovskiy ${ }^{6}$, K.V. Maremyanin ${ }^{7}$, V.I. Gavrilenko ${ }^{7}$

${ }^{1}$ Institute of Ultra High Frequency Semiconductor Electronics of Russian Academy of Sciences, 117105 Moscow, Russia

2 Belarusian State University, 220030 Minsk, Belarus

${ }^{3}$ National Research Nuclear University MEPhl, 115409 Moscow, Russia

${ }^{4}$ National Research University

of Electronic Technology, 124498 Moscow, Zelenograd, Russia

5 JSC Polyus Research Institute of M.F. Stelmakh, 117342 Moscow, Russia

${ }^{6}$ Institute of Radio-Engineering and Electronics

of Russian Academy of Sciences,

125009 Moscow, Russia

${ }^{7}$ Institute for Physics of Microstructures

of Russian Academy of Sciences,

603087 Nizhny Novgorod, Russia

\begin{abstract}
We have designed the active region of the terahertz quantum-cascade laser (QCL) based on three tunnel-coupled quantum wells $\mathrm{GaAs} / \mathrm{Al}_{0.15} \mathrm{Ga}_{0.85} \mathrm{As}$ with a resonance-phonon depopulation scheme. Numerical calculations of energy levels, matrix elements of dipole transitions, the degree of subbands populations and gain spectra are carried out depending on the applied electric field and temperature. It is shown that the maximum gain is realized under phonon resonance conditions at a frequency of $3.37 \mathrm{THz}$ at an electric field strength of $F=12.3 \mathrm{kV} / \mathrm{cm}$. Based on the proposed design, THz QCL emitting at $3.3 \mathrm{THz}$ with an $\mathrm{Au}-\mathrm{Au}$ double metal waveguide and $T_{\max } \sim 84 \mathrm{~K}$ was fabricated. The characteristic energy $E_{a}=23 \mathrm{meV}$, which is necessary for the temperature activation of the emission of LO-phonons in the stimulated recombination of ,hot" electrons from the upper to the lower laser levels, is determined from the Arrhenius graph of the output power from the temperature.
\end{abstract}

